\title{
LA ARQUITECTURA DOMÉSTICA URBANA DE LAS CIUDADES OCCIDENTALES DEL CONVENTUS HISPALENSIS: UN EJERCICIO DE CRÍTICA HISTORIOGRÁFICA ${ }^{1}$ \\ URBAN DOMESTIC ARCHITECTURE OF THE WESTERN CITIES OF CONVENTUS HISPALENSIS: AN EXERCISE IN CRITICAL HISTORIOGRAPHY
}

ÁLVARO CORRALES ÁLVAREZ

Universidad de Huelva

JAVIER BERMEJO MELÉNDEZ

Universidad de Huelva

JUAN MANUEL CAMPOS CARRASCO

Universidad de Huelva

\begin{abstract}
Resumen
La arquitectura doméstica de las ciudades occidentales del Conventus Hispalensis continúa siendo una línea de investigación abierta y aún por desarrollar. Así, a pesar de que existe una literatura arqueológica previa, hasta la fecha, no se había realizado un estudio que presentara una panorámica global que integrara el análisis de su arquitectura, programa ornamental, cultura material y su inserción en la trama urbana, factores explicativos de gran interés en la actualidad, a tenor del desarrollo que la arquitectura doméstica en Hispania ha sido objeto en las últimas décadas (Corrales, 2012, 256). Así, pues, se hacía necesaria la generación de un marco de trabajo teórico (Wallace- Hadrill, 1997, 219) mediante el cual, la edilicia doméstica de las ciudades del territorio onubense se entendiese como una reflexión global, en la que, de la mano de las nuevas evidencias arqueológicas, se pudiera producir una aproximación interpretativa renovada.
\end{abstract}

Palabras claves. Arquitectura doméstica urbana, Conventus Hispalensis, Baetica, Hispania, historiografía.

\begin{abstract}
The domestic architecture of the western cities of Conventus Hispalensis remains an open line of research still being developed. So, even though there is a previous archaeological literature, there had not been a study establishing a comprehensive overview that integrates de analysis of its architecture, ornamental program, material culture and its incorporation into the urban network. All these explanatory factors are currently of great interest due to the importance of the domestic architecture in Hispania in the past decades (Corrales, 2012, 256). Therefore, the generation of a theoretical framework (Wallace-Hadrill, 1997, 219) was necessary in order to globally understand the urban domestic architecture in the ancient cities of the territory of Huelva. Thanks to new archaeological evidence, this could lead to a renewed interpretative approach.
\end{abstract}

Key words. Urban domestic architecture, Conventus Hispalensis, Baetica, Hispania, historiography.

Para citar este artículo / To cite this article: Corrales Álvarez, A., Bermejo Meléndez, J. y Campos Carrasco, J. M. (2016). La arquitectura doméstica urbana de las ciudades occidentales del Conventus Hispalensis: un ejercicio de crítica historiográfica. Lucentum, XXXV, 201-215. doi: 10.14198/LVCENTVM2016.35.11

Para enlazar con este artículo / To link to this article:

http://dx.doi.org/10.14198/LVCENTVM2016.35.11 


\title{
LA ARQUITECTURA DOMÉSTICA URBANA DE LAS CIUDADES OCCIDENTALES DEL CONVENTUS HISPALENSIS: UN EJERCICIO DE CRÍTICA HISTORIOGRÁFICA ${ }^{1}$
}

\author{
URBAN DOMESTIC ARCHITECTURE OF THE WESTERN CITIES OF CONVENTUS HISPALENSIS: \\ AN EXERCISE IN CRITICAL HISTORIOGRAPHY
}

ÁLVARO CORRALES ÁLVAREZ

Universidad de Huelva

JAVIER BERMEJO MELÉNDEZ

Universidad de Huelva

JUAN MANUEL CAMPOS CARRASCO

Universidad de Huelva

\section{INTRODUCCIÓN}

Las investigaciones realizadas por parte de la historiografía tradicional sobre la arqueología onubense habían relegado a un plano marginal los estudios de las ciudades romanas (Bermejo y Campos, 2013a, 393). No es de extrañar, pues, que desde el Área de Arqueología de la Universidad de Huelva, el Grupo de Investigación Vrbanitas. Arqueología y Patrimonio encaminara los primeros pasos en la búsqueda de conocimiento de la sociedad romana, a partir de la documentación arqueológica, en una línea de trabajo con el objetivo general de analizar el fenómeno urbano (Campos y Bermejo, 2013, 8).

A este fin último se llevan consagrados veinticinco años de literatura proyectual (Campos et alii, 1990, 67-106), abordando de forma diacrónica el estudio de poblamiento y territorio con la formación de paisajes culturales y naturales (Campos et alii, 1991, 43-70). En este proceso resultó de vital importancia el estudio de la génesis y evolución del fenómeno urbano en el territorio onubense (Campos, 2002, 161-168), así como el examen de la implantación romana que posibilitó conocer la dinámica de ocupación (Vidal, 2002, 55-76). Asimismo, el atento examen de las fuentes de información de autores grecolatinos ha contribuido, en la última década, a la identificación de nuevas ciudades cuyos testimonios arqueológicos habían permanecido recónditos (Ruiz, 2010; Ruiz y Bermejo, 2013, 19-56).

En la actualidad es posible apreciar al menos seis núcleos urbanos de época romana en el occidente de

1. Este trabajo es producto de las investigaciones desarrolladas en el marco del proyecto de Excelencia del Plan Andaluz de Investigación «CVB I. Corpus Vrbium Baeticarum I. Ciudades Romanas de la Bética» (Ref. HUM2062). la Baetica, a tenor de los resultados obtenidos por la citada línea de investigación. Así, la articulación de este territorio se basa en una red de ciudades capitalizadas por Onoba (Huelva), Ilipla (Niebla), Ituci (Tejada la Nueva. Escacena del Campo), Ostur (Mesa del Castillo. Manzanilla), Arucci (San Mamés. Aroche) y Urium (Riotinto) (Fig. 1). La problemática arqueológica propia que presenta cada yacimiento es diversa, hecho que ha afectado de manera palmaria al grado de conocimiento que de cada asentamiento se tiene. A pesar de ello, en líneas generales, el análisis de la situación previa a la llegada de Roma (Toscano et alii, 2013, 57-86), el estudio de la implantación de Roma en el territorio (Bermejo y Campos, 2013b, 87-108) y la atención a aspectos como la dinámica de municipalización (Bermejo y Campos, 2013c, 109-134) han propiciado una síntesis sobre las ciudades occidentales del Conventus Hispalensis (Campos et alii, 2013, 135-226).

Toda esta documentación, realimentada por un nutrido elenco de investigadores, ha propiciado la consecución de una cota elevada de madurez para la arqueología de los espacios políticos del territorio del Suroeste peninsular. Este hecho ha abierto la puerta a una nueva parcela de la arqueología, centrada en el análisis y discusión de la arquitectura doméstica de época romana. Este campo continúa aun por desarrollar, brindando la posibilidad de emprender esta tarea de investigación desde la sinceridad y el compromiso.

\section{HISTORIOGRAFÍA}

A pesar de que el objeto de estudio del presente trabajo sea analizar la producción bibliográfica de los estudios realizados en torno al ámbito doméstico urbano de las ciudades occidentales del Conventus Hispalensis, se 


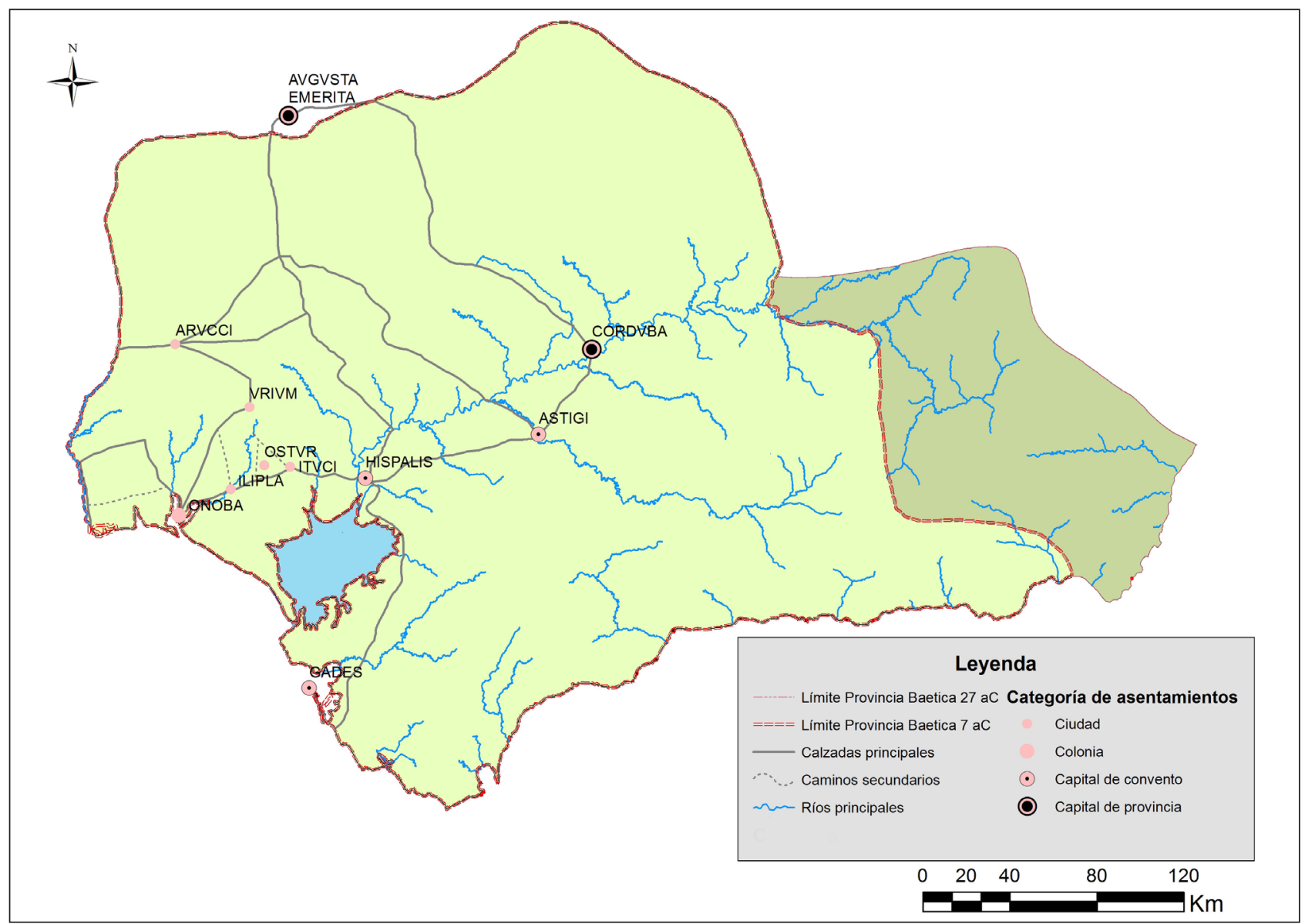

Figura 1: Plano que muestra la localización de las ciudades hispanorromanas occidentales del Conventus Hispalensis (Grupo PAI-HUM 132, Vrbanitas).

considera necesaria una sucinta reflexión previa sobre la manera en que se había ido gestando el conocimiento sobre esta temática en el contexto hispano. Así, pues, la finalidad que nos proponíamos era conocer cómo se había valorado la problemática inherente al estudio de las viviendas de las ciudades romanas del territorio onubense, advertidos que a escala nacional, la historiografía había resultado ser prácticamente ajena a dicha obra (Balil, 1959b, 284). Precisamente, es el profesor A. Balil quien sintetiza, por vez primera, la significación de las casas romanas distribuidas a lo largo de toda la geografía de la Península Ibérica. En el marco de sus investigaciones recaba ya datos de viviendas pertenecientes a la ciudad de Baelo en el Conventus Gaditanus, concretamente sobre la Casa del Reloj de Sol y la Casa del Oeste (Balil, 1959a) y de la ciudad de Italica sobre la Casa número Cinco, la Casa de Hylas, la Casa de los Pájaros y la Casa del Patio Rodio (Balil, 1959a). Sin duda alguna, las informaciones recogidas en este trabajo, están basadas en los datos aportados por los excavadores de las construcciones domésticas, con lo que cabría remontar el interés por el estudio de la edilicia privada en estos núcleos urbanos de la Baetica al menos desde el último cuarto de finales del siglo XIX para Italica (Fernández, 1998) y desde el primer cuarto del siglo XX para Baelo (Paris et alii, 1923).
Sin entrar a valorar de forma extensa la profusa bibliografía sobre el yacimiento italicense debe destacarse que durante el lustro de 1925 a 1930 las excavaciones se centraron en la exhumación de varias casas (Parladé, 1934). Los inmuebles apenas documentados fueron objeto de unos exámenes de mayor calado y puestos en relación con la trama urbana de la ciudad (Carriazo, 1934-1935; Carriazo, 1935; García y Bellido, 1960). A partir de la década de los setenta del pasado siglo XX, los restos arqueológicos son difundidos por medio de una guía que permite llegar a un sector de la sociedad interesado en la historia que supondrá el germen del turismo, centrado en el efectismo dramático de los pavimentos musivos de las viviendas ( $\mathrm{Lu}-$ zón, 1970). En el decenio siguiente, las construcciones domésticas de Italica vuelven a servir como paradigma para un análisis general de las casas romanas en Hispania (Balil, 1974). A la luz de los nuevos hallazgos de viviendas se aplican metodologías específicas para el estudio de su numismática (Chaves, 1974, 205211) y su técnica edilicia (León, 1977-1978, 143-152). Sin embargo, el interés por las producciones musivas (Blanco, 1978) y pictóricas (Abad, 1975, 883-893) continuó acaparando la atención de los trabajos científicos. En los años ochenta del siglo XX, se examina la ocupación del espacio urbano prestando una especial 
atención al paisaje doméstico (Luzón, 1982, 75-95). En las últimas tres décadas, la línea de investigación centrada en el análisis de la arquitectura doméstica se ha mostrado como uno de los campos más dinámicos en la historiografía de la ciudad, si bien los temas tratados no son novedosos debido a la sistematicidad de los estudios precedentes, hay que advertir que los enfoques son diferentes (Blázquez, 1993; Mañas, 2004, 103-124; Mañas, 2011).

En cualquier caso, resulta muy significativo que este núcleo urbano siempre ha tenido representación en los congresos y exposiciones monográficas relativas tanto a las casas (Rodríguez, 1991, 291-302, Roldán, 1991, 303-312) como a las ciudades hispanas de época romana (León y Rodríguez, 1993, 12-53).

¿Qué factores podrían explicar el desigual grado de conocimiento de la edilicia doméstica en núcleos urbanos que se implantan en el territorio occidental de la Baetica y que forman parte de un mismo conventus iuridicus?

Uno de los primeros argumentos que cabría esgrimir radica en la información contenida en los testimonios literarios sobre los núcleos urbanos del territorio onubense. Así, a menudo, con mayor frecuencia de lo que el investigador deseara, los inestimables datos aportados por los autores de la Antigüedad, asignan un mismo nombre a varios lugares geográficos, ya estuviesen estos cercanos o distantes entre sí. Este hecho, sin duda, supone una traba de facto para la identificación de las ciudades. En las fuentes grecolatinas este fenómeno es común en la mayoría de los asentamientos donde se implantaron los romanos, como sucede en los casos de Ilipla e Itucci (Campos y Vidal, 2003, 51). Sin embargo, a pesar de la incuestionable influencia de este primer factor, es la complejidad propia de la trama urbana de la mayoría de las ciudades, la que resulta de gran trascendencia y valor explicativo. En este sentido, la larga tradición urbanística de los asentamientos que articulan este territorio que tienen una ocupación anterior a la implantación romana, un fuerte sustrato de raíz púnica como Onoba (Campos, 2011, 167-190) o Ilipla (Pérez et alii, 2000, 91-122), y que ocupan el mismo solar desde su fundación, representa una de las dificultades endémicas para el desarrollo global de este campo de investigaciones. Además, el parcelario moderno no se corresponde con los predios romanos. Este hecho agrava la dificultad para interpretar el registro arqueológico, por lo que resulta improbable que pueda apreciarse de manera diacrónica la dinámica de ocupación de las construcciones domésticas. Este fenómeno no constituye una excepción de estos asentamientos del Conventus Hispalensis, sino que hay que ponerlo en relación con lo que sucede en otros centros poblacionales y políticos hispanos como $\mathrm{Ta}$ rraco (Macias, 2004, 73), Corduba (Vaquerizo, 2004, 81), Augusta Emerita (Corrales, 2011, 311) o la propia Hispalis (Campos, 1989, 245).

En contraposición a los casos anteriormente citados, los núcleos urbanos de Urium y Arucci no presentaron una trama urbana fruto de una ocupación secular, sino más bien la formación de diferentes zonas de hábitats en relación a las explotaciones mineras, o la mutatio oppidum, que supone el traslado del núcleo prerromano al llano, respectivamente (Campos et alii, 2013, 195 y 202). El hecho de que la problemática relativa a la edilicia doméstica quedase relegada a un segundo plano habría que achacarlo a otros aspectos. En este sentido, cabe advertir como en lo que respecta a Urium se prestó una atención especial a las cuestiones relativas al estudio integral del conjunto de tecno-facturas para obtener información sobre las actividades de obtención, producción, uso, mantenimiento, descarte, técnicas aplicadas, organización y significado de las actividades minero-metalúrgicas (Pérez y Delgado, 2011, 14) o a los paisajes culturales y antrópicos derivados de la extracción de los minerales (Pérez y Delgado, 2012, 47). En el caso de Arucci, la documentación arqueológica que acaparó el interés de los científicos en un primer momento fueron los restos arquitectónicos más monumentales correspondientes a la edilicia pública, primordialmente el área forense (Bermejo, 2010, 999-1010; Bermejo, 2014, 107-125; Bermejo y Campos, 2014, 1561-1566) y el complejo destinado a los espacios termales (Medina, 2010, 1011-1033).

Una vez que se ha expuesto la problemática existente en torno a las viviendas de las ciudades occidentales del Conventus Hispalensis cabría plantearse ¿qué es lo que realmente se conoce del paisaje doméstico de estos núcleos urbanos? Las respuestas constructivas fueron diversas en función de los diferentes modelos de ocupación y poblamiento que cada asentamiento tuvo debido tanto a factores naturales como culturales (Campos y Vidal, 2003, 41), por lo que resulta necesario presentar cada centro de forma individualizada.

En el caso de Onoba, las excavaciones arqueológicas sensu estricto se iniciaron en la década de los setenta del pasado siglo XX (Campos, 2001-2002, 330). En aquellos momentos los restos materiales de la ciudad romana se limitaban a dos factorías de salazones y zonas funerarias, sin haberse producido hallazgo alguno de edificaciones de relevancia de naturaleza pública o privada que perteneciese al hábitat de la población romana. Posiblemente, la tipología de construcciones documentadas se localizaba en la periferia de la población, debiendo situarse el núcleo principal del hábitat romano en la zona comprendida por los cabezos de San Pedro, del Pino, La Esperanza y el Molino del Viento (Amo, 1976, 115). Durante el siguiente decenio, las intervenciones practicadas posibilitaron la lectura de un registro arqueológico de base cronológica más preciso que permitió definir algunas estructuras de habitación. Estos vestigios permitían aludir a una ocupación romana desde el cambio de Era, con un asentamiento de época altoimperial de cierta envergadura, un vacío de evidencias para el siglo II y nuevos elementos desde mediados del siglo III y comienzos del IV. Esta síntesis valoraba el papel 


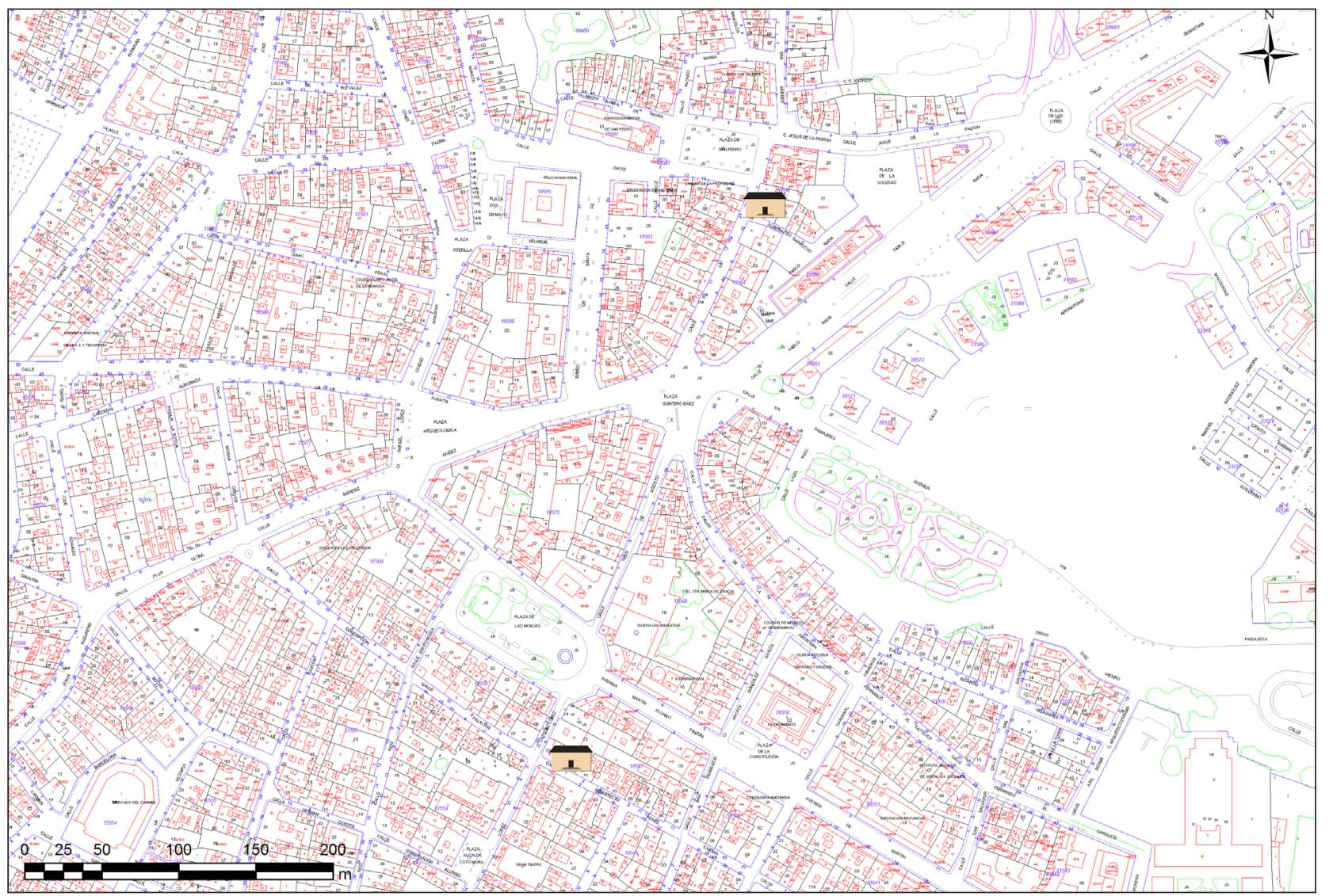

Figura 2: Plano que muestra la ubicación de las viviendas romanas de la colonia Onoba sobre el sistema de predios actual de Huelva (Grupo PAI-HUM 132, Vrbanitas).

de Onoba con escasa trascendencia en el conjunto de la Baetica, sólo destacable durante la época Flavia, en consonancia con otros núcleos urbanos (Fernández et alii, 1992, 289-317; Fernández et alii, 1997, 80). Hubo que esperar a un nuevo hallazgo para replantear estas apreciaciones y cuestionar la escasa entidad con que se había valorado el poblamiento romano (Rufete y García, 1997, 78). Lamentablemente, ninguno de los restos arquitectónicos documentados se adscribió a espacios de residencia, motivo por el cual la edilicia doméstica continuaba siendo completamente ignota.

No será hasta finales de la década de los noventa del siglo XX cuando se identifiquen los primeros restos arquitectónicos de una casa romana en Onoba (Fig. 2). Los vestigios se documentaron a raíz de dos sondeos diferentes, hecho que da muestra de la fragmentariedad de los hallazgos y la imposibilidad de conocer las relaciones topológicas entre las estructuras registradas, a pesar de ello fue posible advertir dos fases de ocupación. La primera etapa se caracterizó por la presencia de estructuras en ambos cortes. En el primero de los cortes se examinó, posiblemente, el cierre exterior de una construcción doméstica y varios muros fabricados con cimientos de pequeñas lajas colocadas verticalmente y alzados de piedras menudas y fragmentos de ladrillos. Uno de los muros mejor conservado presentó una técnica edilicia a base de lajas de pizarra trabajadas en ambas caras. En las habitaciones no se apreciaron restos de pavimentos asociados a los muros. Afortunadamente, en el segundo corte, los restos se hallaron mejor preservados. Así, se documentaron varios muros erigidos con una misma técnica constructiva que delimitaban tres espacios diferentes. Dos de estas habitaciones poseerían una decoración estucada. Además, se registró un suelo de opus signinum en una de las estancias. El diferente tratamiento de estos últimos ambientes podría indicar su identificación con espacios de distinta funcionalidad correspondientes a una misma vivienda o bien a dos diferentes (Mercado y Mejías, 1999).

A esta unidad constructiva se asociaron fragmentos de T.S.Hispánica, de imitación de T.S. Itálica, campaniense y común. Estos materiales plantearon una adscripción cronológica al siglo I (Mercado y Mejías, 1999; Campos y Gómez, 2000; Gómez, 2010, 305306), con posterioridad se ha precisado que las piezas de T.S. Hispánica pertenecen a época de Claudio, las imitaciones son producciones aretinas y que también se vincularon jarritas de cerámica gris (Campos, 2011, 92).

El segundo momento de ocupación estaría representado por las estructuras documentadas en el primero de los cortes, hecho que resulta significativo por la inexistencia de construcciones en el segundo sondeo. Los responsables de la excavación advierten que dicha cuestión podría explicarse por un posible abandono o 
sobre elevación de los muros precedentes, dado que se apreció la misma ordenación y dirección de las estructuras. Asimismo, se planteó como hipótesis de trabajo que la ausencia de construcciones en el corte segundo podría deberse a que no se tratase de un área habitada o bien, que se correspondiese con un espacio abierto. Así, se documentaron restos de dos muros que conformaban el ángulo de una habitación. La técnica edilicia de los paramentos es de tierra compactada, pequeñas piedras y fragmentos de lajas de pizarra. La anchura máxima registrada fue de $0,60 \mathrm{~m}$ y presentó un revestimiento de cal y arena con decoración. La estancia estaba pavimentada con un suelo de opus signinum. En lo que respecta a la decoración, el zócalo de color rosáceo estaba separado de los paneles a través de líneas rojas, amarillas y blancas. Dichos paneles presentaron unas dimensiones de $1 \mathrm{~m}$ y $1,13 \mathrm{~m}$ de ancho y correspondían a una imitación de mármol brocatel. Estos cuerpos se separaron por bandas rojas, con imitaciones al interior decoradas con líneas rojas o negras y relleno en ocre. (Mercado y Mejías, 1999). La cultura material vinculada a esta unidad constructiva fue un conjunto de fragmentos de T.S. Africana y común. Estas cerámicas permiten datar la segunda fase de ocupación en el siglo III (Mercado y Mejías, 1999).

A finales de 1999 se asiste a una nueva concepción de la arqueología urbana onubense, debido a dos hechos trascendentales. Por una parte, desde la Universidad de Huelva se elaboró la Carta de Riesgo (Campos y Gómez, 2000; Gómez y Campos, 2000, 158). De otra parte, como consecuencia del documento redactado tuvo lugar la Incoación del expediente de la Zona Arqueológica de Huelva, que posibilitó la multiplicación de excavaciones sistemáticas de carácter científico y técnico (Campos, 2011, 59). Fruto de una de estas intervenciones se documentó parte de la zona trasera de una edificación, por lo que resultó difícil valorar si se trataba de un espacio público o privado (Guerrero et alii, 2004, 522). Sin embargo, en otro artículo, los mismos autores se habían decantado por una funcionalidad netamente doméstica. En el citado trabajo, los restos arquitectónicos registrados se correspondían con un peristilo con un pasillo perimetral, cuyo porticado se apoyaría sobre un muro de $0,50 \mathrm{~m}$ de anchura, donde las columnas de ladrillo arrancarían de un pedestal elaborado con el mismo tipo de material constructivo. Además, el patio porticado poseería en el centro algún tipo de «juego de agua», a juzgar por la documentación de una canalización (Pérez et alii, 2003, 174-175). La interpretación de estos vestigios como edificio de naturaleza residencial fue refutada ya en el pasado en diversos trabajos, que asimilaban la funcionalidad del edificio, bien con una industria o artesanía (Gómez, 2010, 363), bien con una función comercial (Campos, 2011, 93-94).

En este sentido, a tenor de los resultados obtenidos en la excavación, que corroboraron el uso del área denominada patio como depósito de ánforas vinarias, olearias y dolia, con una funcionalidad de almacenamiento (Guerrero et alii, 2004, 522), la documentación de unos muros con un grosor de $0,70 \mathrm{~m}$, que podrían indicar la existencia de un piso superior, (Pérez et alii, 2003, 174), así como la ubicación del edificio en la zona portuaria de Onoba, resulta razonable pensar que el edificio documentado se corresponda en realidad con la planta baja de un negocio comercial, que bien pudiera tener un espacio de residencia en la planta alta. La cronología del edificio se define entre los años 40 y 80 del siglo I debido a su cultura material, sin embargo, convendría revisar esta datación, habida cuenta de las contradicciones estratigráficas detectadas en las publicaciones (Campos, 2011, 93).

Esta hipótesis, de habitación en altura y tienda en la planta baja, resulta muy verosímil si se atiende tanto a los testimonios literarios de autores clásicos, como a las construcciones domésticas del área vesubiana. Así, el tendero Pompeius Diogenes, compañero liberto de Trimalción, viviría en una habitación encima o detrás de la tienda, pero su prosperidad es grande y «desde las calendas de Julio alquila casa porque quiere comprar otra» (Satiricón 38). En el caso de Pompeya, un estudio recoge que el $40 \%$ de talleres y tiendas contaban con escaleras que conducían a una habitación situada en una planta superior, donde se han registrado hogares, letrinas o almacenes (Gassner, 1986, 32-40). En los casos en que se han registrado escaleras hacia una planta superior es de suponer que en ese espacio vivirían el tendero o su asistente (tabernarius, institor) y una familia reducida, como debió suceder en el edificio I, 6, 10 (Wallace-Hadrill, 1991, 209-211). Otro de los yacimientos que ofreció una buena muestra de evidencias en consonancia con la hipótesis de trabajo expuesta es Herculano, donde un estudio confiere una especial atención a las funcionalidades y la superficie útil de este tipo de inmuebles (Andrews, 2006). Finalmente, resultan de vital importancia ejemplos similares de plantas que pueden documentarse en otras colonias marítimas como Ostia, caso de la pequeña tienda situada en la esquina sur del Piccolo Mercato I, VIII, 1 (Packer, 1971,6) en la Península Itálica, o Tarraco, caso de la vivienda de la avenida Prat de la Riba, ${ }^{\circ}$ 9, que contó con un espacio para almacenaje (Cortés, 2014, 575), en la Península Ibérica.

En última instancia, cabe aludir a los restos arqueológicos registrados en la Plaza San Pedro, 4-5. Según sus excavadores, de acuerdo al contexto material, presencia de cerámica campaniense y T.S. Sudgalica del tipo Drag. 17 y material anfórico con las formas Pellicer D, en la fase romana republicana este predio debió de estar ocupado por una vivienda, de la que se habrían documentado varias estancias que conformarían dos ambientes principales. De una parte, se alude al atrio a raíz de dos bases cuadrangulares de pizarra sobre las que suponen la existencia de pilares, con un solado de adobe y arena compactada. De otra parte, tres habitaciones cuya funcionalidad no pudo ser precisada. No obstante, se aventura un modelo de construcción doméstica de planta rectangular de tradición 


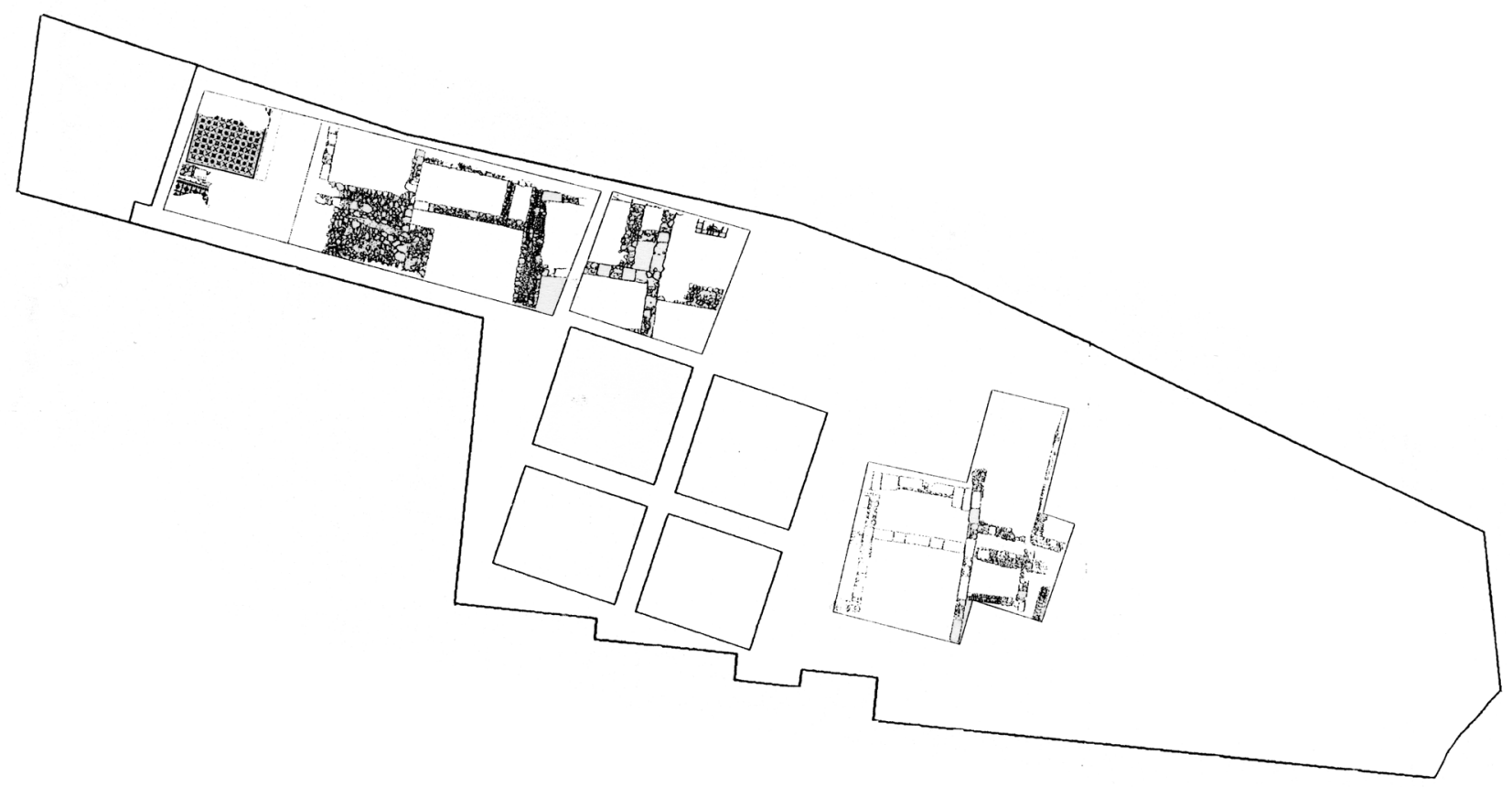

Figura 3: Planimetría que muestra las viviendas documentadas en el sector de la Puerta de Sevilla de la ciudad de Niebla (a partir de Belén, Fernández, Amo, Balbín y Tejera, 1983, fig. 1).

turdetana pero construida con una fórmula arquitectónica de prestigio romana como es el atrio (González y Guerrero, 2008, 300-301). Si bien es cierto que no procede descartar con rotundidad que se trate de un edificio doméstico, cabe advertir que lo exiguo de las evidencias aportadas y el contexto topográfico funerario de la ciudad en fase altoimperial (Fernández et alii, 2013, 176) no permiten corroborar esta hipótesis. Por tanto, conviene tomar con cautela la interpretación de estos restos arquitectónicos con carácter doméstico.

Las primeras noticias sobre la ciudad romana de Niebla se remontan al siglo XVII, de la mano de R. Caro (1634), pero no será hasta finales del siglo XIX cuando este interés desemboque en la acometida de algunas prospecciones por parte de L. Siret y su capataz, P. Flores, en su territorio. En lo que respecta al núcleo

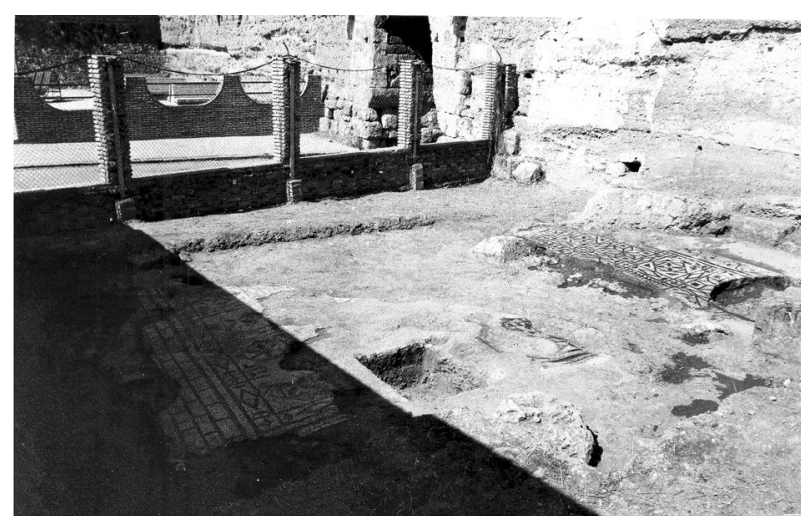

Figura 4.1: Vista de detalle de una de las estancias pavimentadas con mosaico de una de las casas registradas en el sector de la Puerta de Sevilla de la ciudad de Niebla (Rebollo, 1990, fig.1). urbano, las excavaciones pioneras cabría atribuirlas a la Escuela Anglo-Hispano-Americana que, desde su creación en 1914 y hasta finales de la década de los años treinta, intervino en varios puntos de la ciudad. Si bien es cierto que Ilipla había captado el interés de los arqueólogos con anterioridad, no comenzó a ser investigado de manera sistemática hasta la década de los ochenta del pasado siglo XX por parte de la Universidad Complutense de Madrid, centrada en la zona de la Puerta de Sevilla (Pérez et alii, 2000, 92-93). Desde mediados de los noventa, la Universidad de Huelva puso en marcha un proyecto de arqueología sobre la evolución histórica del urbanismo de la ciudad, modificando algunas hipótesis sobre la trama urbana y la extensión del recinto amurallado (Campos et alii, 2002, 35-54).

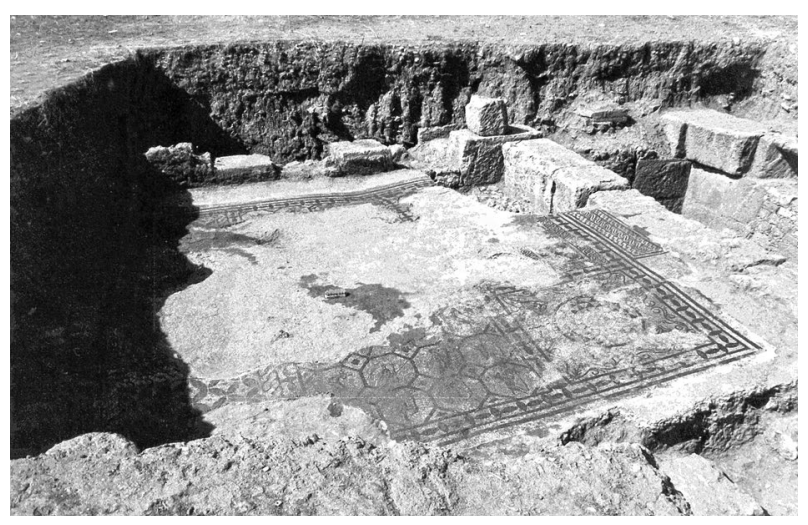

Figura 4.2: Vista de detalle de una de las salas soladas con pavimento musivo de una de las construcciones domésticas documentadas en la zona de la Puerta de Sevilla de la ciudad de Niebla (Rebollo, 1990, fig. 2). 
El paisaje doméstico de Ilipla conocido hasta la fecha se corresponde con cinco viviendas, cuatro de las cuales se documentaron en el área de la Puerta de Sevilla - Fig. 3 - (Campos et alii, 2006, 345-346; Gómez, 2010, 306-307; Campos et alii, 2013, 161-162). A pesar de haber sido registradas todas las casas en una misma zona arqueológica, la fragmentariedad de los datos y la inconexión de los diferentes contextos son las notas dominantes. A esta sintomatología cabría añadir la desigualdad latente entre el análisis de los aspectos decorativos y el examen de las restos arquitectónicos, dado que la documentación de los pavimentos musivos acaparó el interés de las investigaciones (Vidal et alii, 2007, 291-316; Campos et alii, 2008, 55-70; Campos et alii, 2010, 1034-1065).

En este sentido, de la primera de las construcciones domésticas sólo se conocen dos estancias cuyos paramentos eran de tapial revestido de estucos. Dichas habitaciones se construyeron sobre estructuras de época precedente con las que compartían una misma orientación, adscribiéndose los ambientes domésticos a época republicana (Fig. 4) (Belén et alii, 1983, 971994; Rebollo, 1987, 516-520; Belén y Escacena, 1990, 167-306). De una segunda vivienda restarían tres habitaciones construidas con muros de sillares dispuestos a modo de opus quadratum pavimentadas todas ellas con producciones musivas. Uno de los ambientes presentó un mosaico bícromo con motivos geométricos (Vidal et alii, 2007, 294; Campos et alii, 2008, 58-60) mientras que los pavimentos de las otras salas eran polícromos, con motivos geométricos o vegetales, por lo que se adscribieron a una cronología imperial, a caballo entre finales del siglo II e inicios del siglo III Fig. 5 - (Belén et alii, 1983, 971-994; Rebollo, 1987, 516-520; Belén y Escacena, 1990, 167-306; Campos et alii, 2006, 345-346).

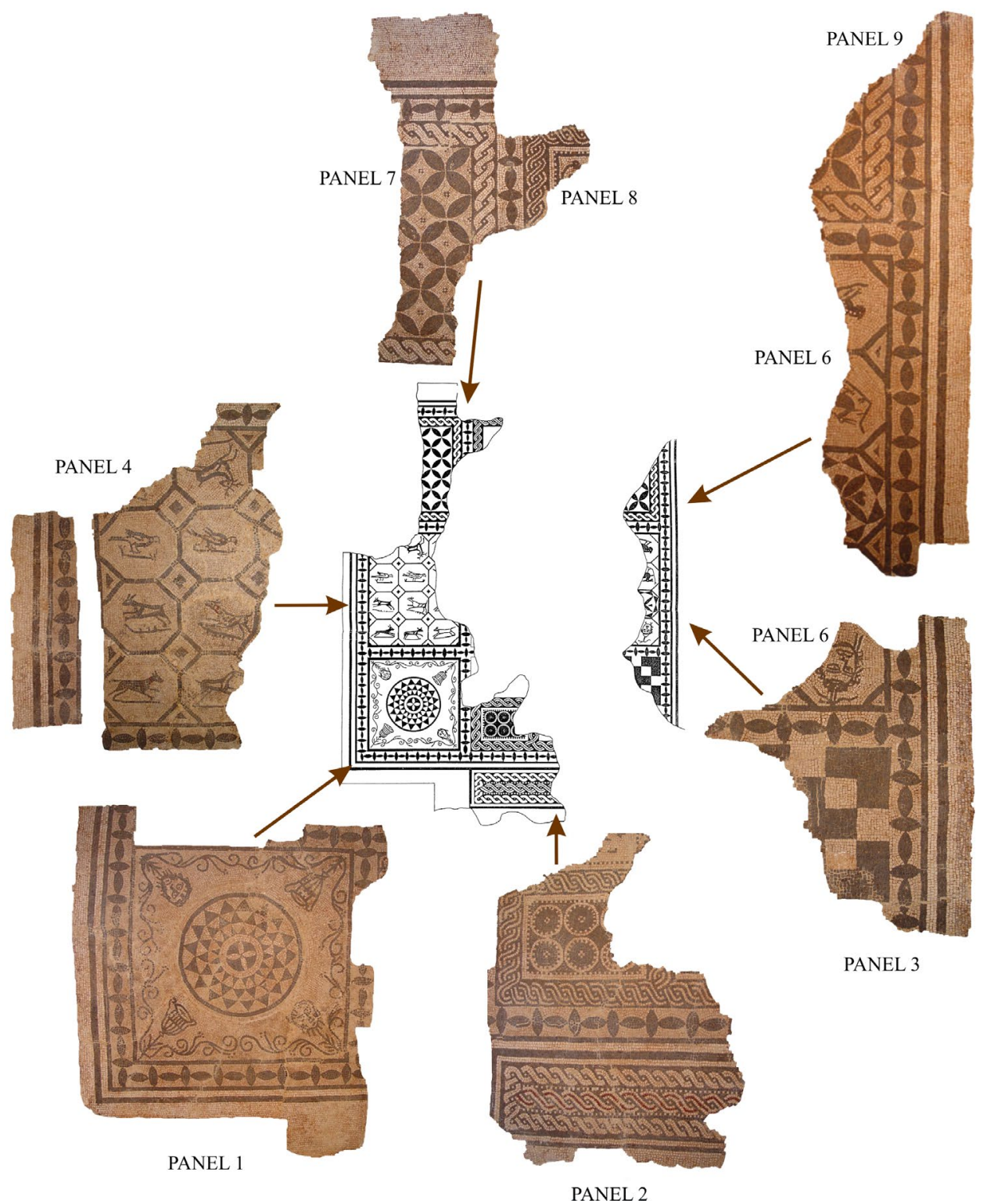

Figura 5: Composición de los diferentes paneles que conforman una de las producciones musivas de una de las domus halladas en Puerta de Sevilla - Ilipla - (Campos, Gómez y Vidal, 2008, lám. 32). 


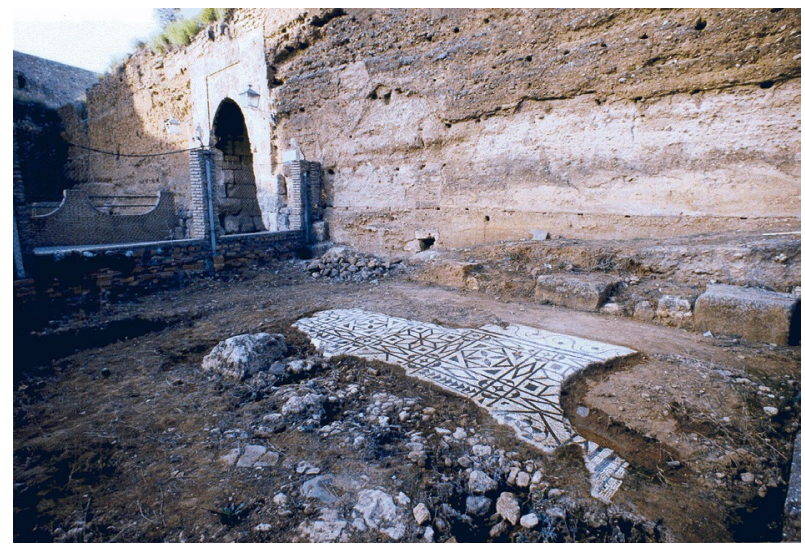

Figura 6: Vista de detalle de uno de los mosaicos pertenecientes a una residencia de la ciudad romana de Niebla (Campos, Gómez y Vidal, 2008, lám. 28).

El tercero de los contextos residenciales está representado por dos habitaciones puestas en comunicación mediante un vano. Cada una de las dependencias poseía un suelo con una técnica edilicia diferente. Así, mientras que una estancia estaba pavimentada con opus signinum, la otra presentó unos cimientos de piedra sobre los que se dispuso una cama a base de cal y arena. Los muros de esta última habitación se construyeron en opus mixtum a base de piedras heteronométricas, revestidos con estucos de motivos geométricos y vegetales de color rojo, negro, verde y ocre. Esta vivienda está datada de acuerdo a su cultura material desde el siglo I a.C. hasta el siglo I d.C., a partir de paredes finas, T.S. y cerámica común (Belén et alii, 1983, 971-994; Rebollo, 1987,5 16-520; Belén y Escacena, 1990, 167-306; Campos et alii, 2006, 345-346). La última vivienda documentada en la zona de la Puerta de Sevilla se encontraba separada de la anterior mediante un muro medianero de sillares que actuaba a modo de ambitus. De este inmueble se han conservado dos habitaciones cuyos paramentos se construyeron con sillares y estaban comunicadas entre sí mediante un vano (Fig. 6). La habitación meridional se encontraba pavimentada con una producción musiva polícroma y poseía una iconografía variada: motivos geométricos, faunísticos y antropomorfos. La estancia septentrional se pavimentó con un mortero a base de cal. Presumiblemente, los muros de estos ambientes debieron estar revestidos de estuco como atestiguaría la ingente cantidad de fragmentos de este tipo de decoración asociados con la fase de amortización de la casa. De acuerdo a los restos de cultura material (fragmentos de ARSW), así como a la técnica de ejecución de los mosaicos (policromía), los restos se adscribieron cronológicamente al siglo III (Belén et alii, 1983, 971994; Rebollo, 1987, 516-520; Belén y Escacena, 1990, 167-306; Campos et alii, 2008, 61-70).

Finalmente, se tienen indicios de otra posible vivienda romana construida en el siglo II, durante el período adrianeo, situada en la actual calle Altozano, $\mathrm{n}^{\circ} 3$, de la que procede un fragmento de mosaico de aproximadamente $20 \mathrm{~m}^{2}$ (Arnold, 2012, 34-35). La

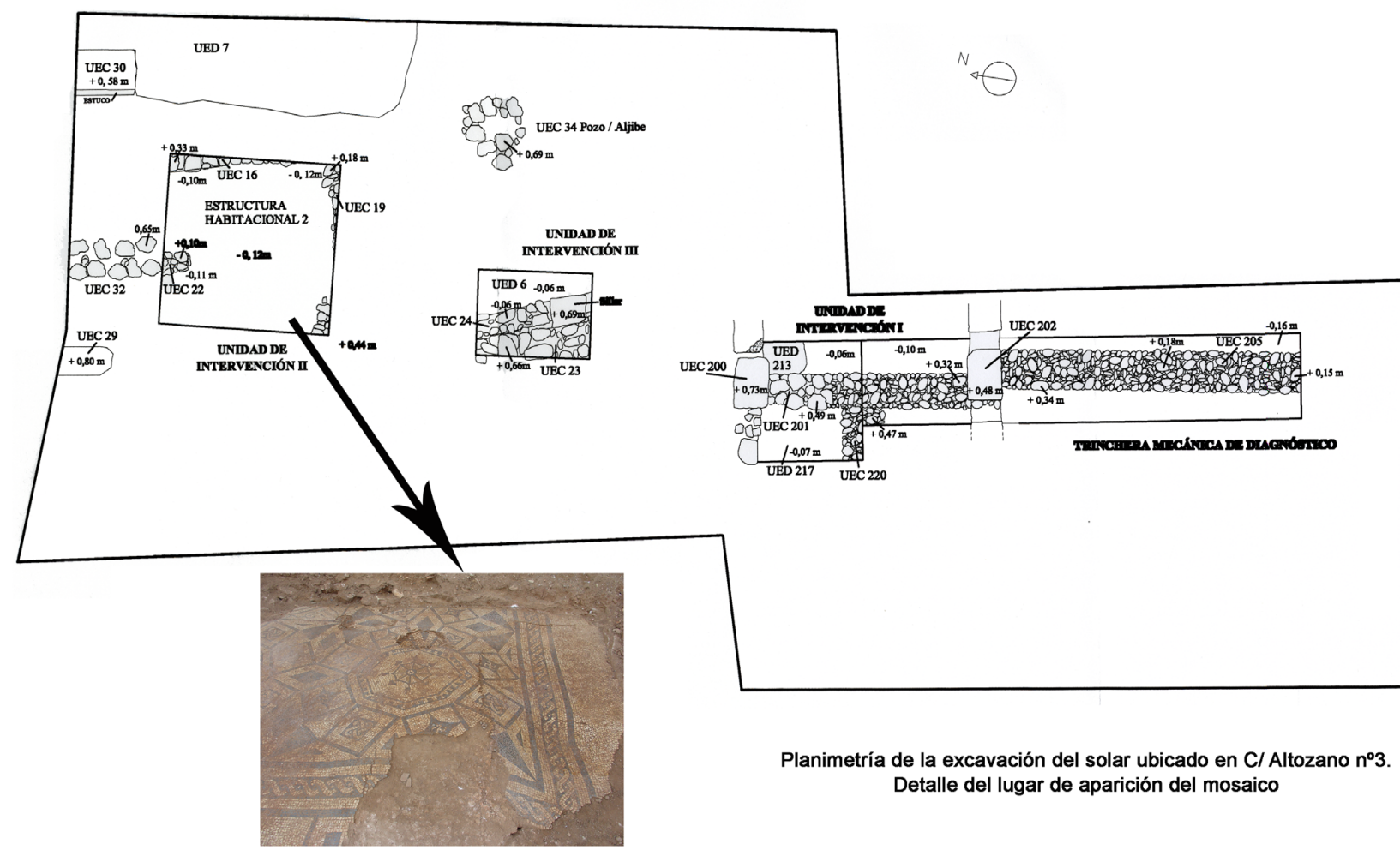

Figura 7: Vista de detalle del pavimento musivo hallado en el predio urbano de la calle Altozano $\mathrm{n}^{\mathrm{o}} 3$ de Niebla (a partir de Arnold, 2012, plano 01). 
composición del pavimento musivo es de naturaleza geométrica, con cenefa exterior formada por nudo de salomón y desarrollo interior con tablero de escaques regulares que enmarcan una sucesión de cuadrados decorados en su interior con diferentes motivos geométricos y florales (Fig. 7). En la parte central debió representarse un gran medallón como así evidencia el pequeño fragmento de ángulo descubierto, y que continúa bajo el perfil del predio urbano colindante. La técnica de ejecución predominante es la bicromía si bien pueden advertirse inserciones de tessellae rojas y de pasta vítrea verde que decoran los pétalos de las representaciones florales.

El núcleo urbano de Ituci (Tejada la Nueva. Escacena del Campo) es una de las ciudades romanas del territorio onubense más desconocidas hasta la fecha (Campos et alii, 2013, 181). Si bien es cierto que su presencia en fuentes textuales, la documentación de sus amonedaciones, así como el registro de un perímetro amurallado de cierta extensión son buenas muestras de la importancia de este asentamiento en el contexto del territorio onubense (Vidal, 1996; Vidal, 1997, 31-45; Campos y Vidal, 1999, 229-236; Vidal, 2002, 55-76; Vidal, 2007), no es menos cierto que las investigaciones sistemáticas se encuentran aún en un estado embrionario. Lamentablemente, la ausencia de evidencias arqueológicas relativas a la arquitectura doméstica urbana es total, por lo que las viviendas de los habitantes de la ciudad de Ituci resultan desconocidas en la actualidad.

El caso del asentamiento de Ostur (Mesa del Castillo. Manzanilla) resulta similar al anterior. Sin embargo, esta ciudad hispanorromana no es mencionada en las fuentes literarias grecolatinas, hecho que dificultó su identificación (Robles, 2012, 105), por lo que tan sólo algunos fragmentos arquitectónicos (Robles, 2011), así como testimonios epigráficos, escultóricos o numismáticos servían para reivindicar su existencia (Robles et alii, 2012-2013, 75-94). Los trabajos de prospección intensiva realizados posibilitaron el examen del trazado amurallado en todo su recorrido así como la recogida de material en superficie. El estudio ceramológico permitió datar el yacimiento con una cronología que abarca desde el siglo II a.C. hasta finales del período altoimperial (Campos et alii, 2013, 184-186). El estado actual de las investigaciones en materia urbanística y arquitectónica está aún abierto y por desarrollar por lo que las construcciones domésticas de Ostur permanecen hoy día sin documentación disponible para su estudio.

En el panorama de las ciudades occidentales del Conventus Hispalensis el núcleo urbano de Arucci (San Mamés, Aroche) es con diferencia el mejor conocido en cuanto a urbanística y proceso histórico (Fig. 8). Los trabajos arqueológicos llevados a cabo, desde finales de la década de los noventa del pasado siglo XX y sobre todo, a partir del año 2004 han posibilitado la estimación de una superficie de entre 1314 hectáreas, incluyendo el ámbito periurbano más próximo. Entre la metodología de intervención aplicada cabe destacar tanto prospecciones superficiales como geofísicas así como excavaciones (Campos et alii, 2013, 201-204). Sin duda alguna, dos de los factores que permiten explicar esta imagen son el hecho de que el yacimiento haya sido objeto de un plan sistemático de actuaciones así como la circunstancia de que no fuera afectado por la ocupación prolongada en el tiempo hasta época contemporánea. Fruto de estas intervenciones, la edilicia doméstica es conocida por la excavación parcial de la Casa de la Columna (Gómez, 2008, 364-374; Gómez, 2010, 364-365; Bermejo, 2013, 206-216), la excavación de planta íntegra de la Casa Norte (Gómez et alii, 2010, 155-175; Bermejo, 2013, 216-225; Bermejo et alii, 2014, 41-50) y la Casa del Peristilo, de la que sólo se conoce su planta mediante los resultados de la prospección geofísica (Bermejo, 2013, 225-226). Asimismo cabría añadir que el paisaje doméstico conocido se implementa con la excavación de parte de las fachadas de otras viviendas. Este hecho evidencia que la dinámica de ocupación residencial de la ciudad sea uno de los elementos más destacados del urbanismo del yacimiento (Campos et alii, 2013, 210).

La Casa de la Columna debió ocupar una de las manzanas residenciales centrales en la trama urbana, equidistante del foro y del sector norte de la muralla del asentamiento (Fig. 9). En el estado actual de las investigaciones se ha excavado una superficie de 128 $\mathrm{m}^{2}$ útiles pertenecientes a una sola fase de ocupación, altoimperial (Gómez, 2008, 366; Bermejo, 2013, 206). A pesar de que la extensión total en planta nos es desconocida, el registro micro-espacial aplicado posibilitó documentar hasta diez ambientes diferentes con un análisis diacrónico que permitió crear una lectura subfásica, en función del material arqueológico examinado. El primer momento de ocupación delimitado abarcó desde fines del siglo I a.C. (época fundacional de la ciudad) hasta mediados del siglo I d.C. Los muros de la estancia IV y V evidenciaron una técnica edilicia homogénea a base de cantos de río de similares formatos. Este sector de la vivienda debió sufrir un incendio a mediados del siglo I d.C. que podría haber puesto fin a esta fase de ocupación (Bermejo, 2013, 208-209).

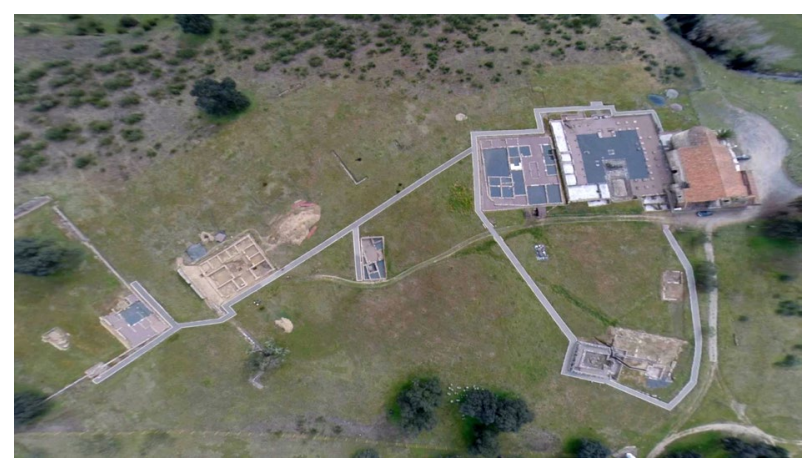

Figura 8: Fotografía área del yacimiento de la ciudad de $\mathrm{Arucci}$ (San Mamés, Aroche) (Grupo PAI-HUM 132, Vrbanitas). 


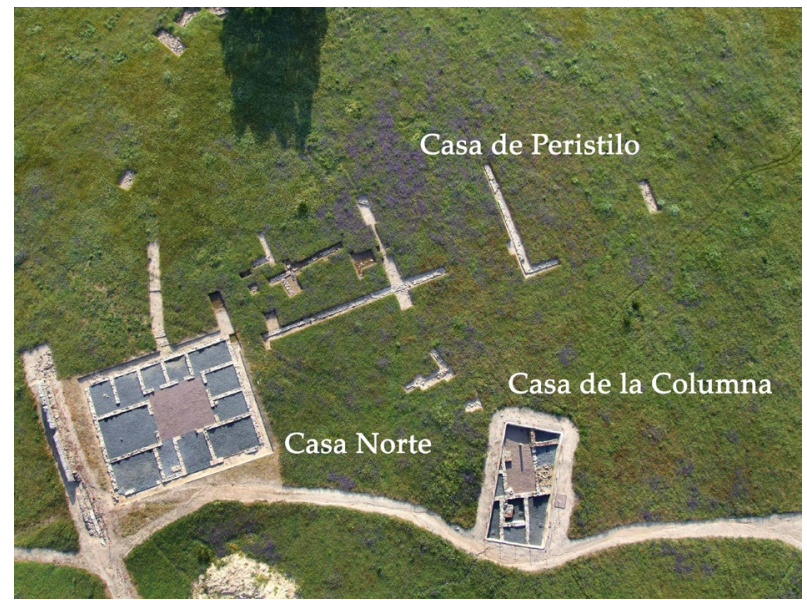

Figura 9: Fotografía área de una de las áreas de residencia del yacimiento de Arucci (Grupo PAI-HUM 132, Vrbanitas).

El segundo momento documentado de la Casa de la Columna corresponde a la segunda mitad del siglo I d.C. y primera mitad del siglo II d.C. y definió prácticamente la totalidad del espacio residencial exhumado. Durante la fase II A, se asiste al recrecimiento de los muros de las habitaciones IV y V que mantienen la orientación de la fase I pero, sobre todo, se multiplican los ambientes advirtiéndose hasta siete nuevas salas, articuladas en torno a un espacio abierto de circulación principal. En lo que se refiere a la técnica constructiva debe destacarse la introducción del ladrillo presente tanto en elementos de sustentación como en soluciones de esquina que dotan de mayor estabilidad la estática del edificio. La ordenación espacial y distribución de algunas estancias cambió respecto a su planteamiento original en un momento que no pudo delimitarse con precisión, dando lugar a la fase II B. Durante esta etapa se obliteró el vano que comunicaba las dependencias IV y V que, junto a la habitación VI, debieron usarse como zona de almacenamiento, al menos hasta la fase II A, a juzgar por la cultura material registrada (Bermejo, 2013, 209-213). En último término, la fase III

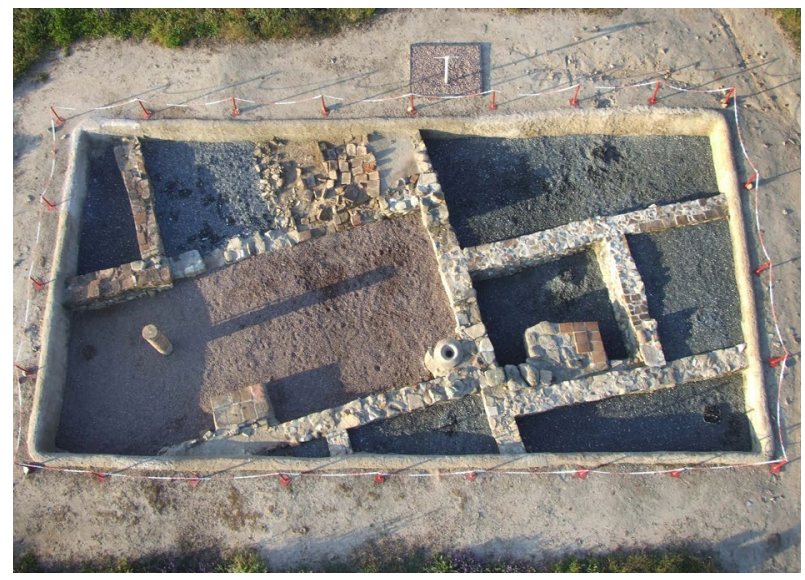

Figura 10: Fotografía área de la Casa de la Columna (Grupo PAI-HUM 132, Vrbanitas).
A conllevó la transformación de algunas habitaciones, como los cambios de pavimentos de las estancias $\mathrm{V}$ y IV y la adición de estructuras en ésta última y en el espacio abierto organizador, relacionadas con actividades de carácter económico para la transformación de alimentos, a la vez que se habilita un área de cocina. Finalmente, la fase III B, datada por la cultura material a finales del siglo II e inicios del siglo III d.C. (Fig. 10), evidencia el momento de abandono de la casa (Bermejo, 2013, 214-216). En lo que respecta a la Casa Norte debe advertirse que el estado actual de las investigaciones permite arrojar una cronología preliminar de construcción para la misma en los primeros decenios del s. I d.C., casi coincidiendo con el momento fundacional de la ciudad. Así, se sabe que la vivienda ocupó una manzana residencial entera de 20,92 m de largo por $16,40 \mathrm{~m}$ de ancho, extendiéndose por una superficie total de $343 \mathrm{~m}^{2}$ (Bermejo, 2013, 216-217).

La vivienda se articuló en torno a un espacio central, un atrio tetrástilo que da acceso a un total de diez estancias, de las que se excluyen dos tabernae, abiertas únicamente a la vía principal que ordenaba el eje norte-sur de la ciudad y que debieron ser puestas en explotación por personas ajenas a la vivienda mediante el pago de alguna renta en concepto de alquiler (Fig. 11). El diseño de planta de la Casa Norte no resulta canónico respecto al eje axial vestibulum-atrium-triclinum, ya que el comedor se dispuso en la crujía occidental. A modo de hipótesis de trabajo se asimilaron varias funcionalidades a algunas estancias como la H12, identificada con la culina o los cubicula asimilados con los ambientes H1-H5, así como las salas H7 y H8 (Bermejo et alii, 2014, 48-49). Sin embargo, hoy día, una vez agotado el registro estratigráfico, el instrumentum domesticum ha posibilitado identificar de forma concluyente la H12 con la cella ostiaria, y las $\mathrm{H} 4$ y H5, como la cella penaria y la culina, respectivamente. La H6 es la gran sala de representación, probablemente un oecus o un triclinium.

La casa de Peristilo no ha sido excavada aún, por lo que su planimetría sólo es conocida mediante el

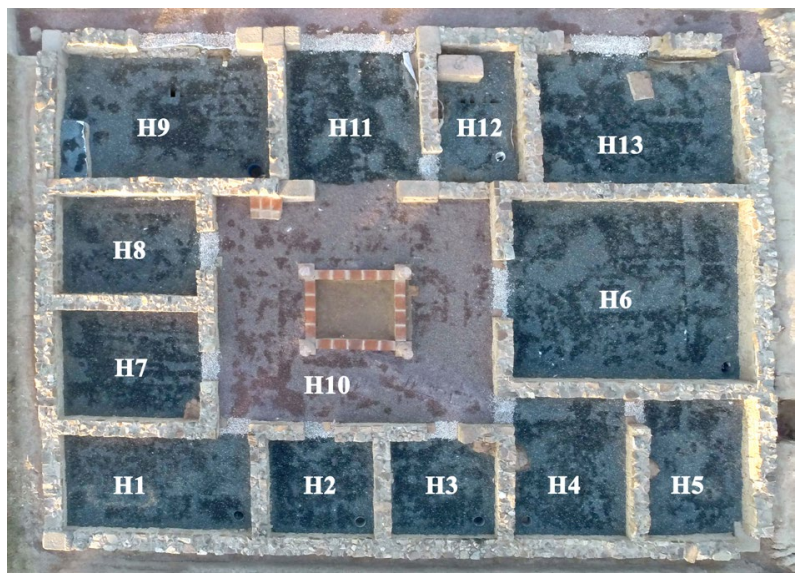

Figura 11: Fotografía área de la Casa Norte (Grupo PAI-HUM 132, Vrbanitas). 


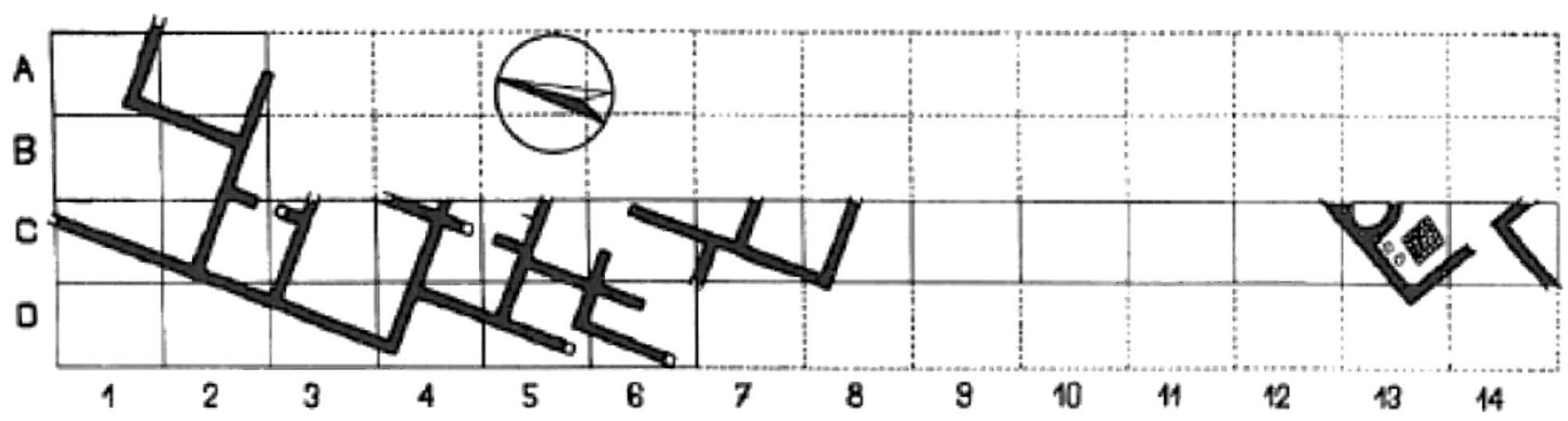

Figura 12: Plano de las excavaciones de Vrium (Luzón y Ruiz, 1970, fig. 5).

empleo de una metodología de prospección geofísica. En este sentido las hipótesis preliminares aventuran un diseño en planta de grandes dimensiones que respondería a la combinación de dos fórmulas de prestigio como son el atrio y el peristilo - Fig. 11 - (Bermejo, 2013, 225-226).

La identificación de los restos romanos de Corta del Lago en Río Tinto con Urium supuso uno de los primeros pasos hacia la comprensión del poblamiento en la zona minera del Suroeste hispano (Luzón y Ruiz, 1970, 125-138). El estado actual de las investigaciones estima probado que el interés por controlar la explotación sistemática de la producción minera, dirigida a las acuñaciones, y el temor a la concentración de capitales en otras manos ajenas a sus designios hizo que, tanto Augusto como Tiberio intervinieran con un dominio efectivo en las minas onubenses (Chic, 2007, 26). El metallum de Urium se conformó así como un distrito militarizado fijado a partir de un praesidium (Cerro del Moro) y de diversos castella en el perímetro del distrito minero (Pérez et alii, 2009, 37-64), que posibilitaron la autonomía de este territorio (Pérez y Delgado, 2007, 125-126).

A pesar de que la posibilidad de trabajo y negocio que suponían la extracción del mineral debió ser un factor atractivo de población de primer orden y considerando vital cubrir la necesidad de habilitar zonas de residencia para los mercenarius o servus que, con su trabajo, garantizasen la solvencia del erario público imperial (Blanco y Luzón, 1966, 73-84), el carácter urbano de estos enclaves resultaba difícil de asumir, debido a la dispersión del hábitat, en directa relación con la explotación de los diferentes filones de mineral del Cinturón Ibérico de Piritas (Campos et alii, 2013, 200).

Este panorama de poblamiento disperso (Pérez, 1986, 135-148) posee una secuencia cronológica amplia. Así, a la denominada Fase VII, datada por su cultura material (ollas de cocina y fragmentos de cerámicas campanienses) en el siglo II a.C., se superpone la Fase VI, que evidenció las primeras estructuras de hábitat, dando paso a la reconstrucción del poblado que caracterizó la Fase V, destruido y amortizado a lo largo del siglo I a.C., en relación directa con la rebelión sertoriana. Durante el período tardorepublicano fue utilizado como escorial (Fases IV y III). La Fase II constituyó el momento en el que Corta del Lago se convirtió en el paraje principal de habitación de las minas de Riotinto: Fase II C se correspondía con la construcción del poblado adscrito a la etapa JulioClaudia; la Fase II B se asocia al período Flavio y la Fase II A que dataría del siglo II d.C. Sin embargo, las evidencias de edificios domésticos más destacables se asocian a la Fase I superficial, ya de cronología tardorromana (Fig. 12), que subrayó el mantenimiento de las actividades minero-metalúrgicas (Campos et alii, 2013, 196-197). La técnica edilicia de los muros construidos en esta última fase, escorias de superficies más o menos planas trabadas con barro, de unos 0,50 $\mathrm{m}$ de ancho, arrancaba directamente del suelo sin que mediase ningún tipo de cimentación. La orientación norte-sur de las viviendas indicaba una planificación urbana (Luzón y Ruiz, 1970, 136). El empleo constatado de la pizarra, tanto en las pavimentaciones como en los ángulos a modo de solución de esquina, se debe, probablemente, a la distribución natural de estos materiales en la geología de la zona, que favoreció un buen ritmo de disposición de los mismos y el abaratamiento en los costes.

Finalmente la identificación de dos esculturas de Claudio y su abuela Livia, datadas entre el 41-54 d.C. (Schattner, 2007, 207-226) así como las inscripciones monumentales halladas en el mismo contexto, sugieren la existencia de un lugar público, bien una plaza o un foro, o bien un praetorium del representante imperial del distrito minero (Gimeno y Stylow, 2007, 227-234). De la mano de estas nuevas evidencias arqueológicas es posible producir una aproximación interpretativa renovada donde todo el distrito minero tuviera un lugar de representación común, debiendo dejar de negar el rango de núcleo urbano para Vrium.

\section{BALANCE Y PERSPECTIVAS DE FUTURO}

Al hilo del desarrollo de los proyectos de investigación sobre el fenómeno urbano en el occidente de la Baetica, hace casi una década que se asentaron las bases para el estudio de las viviendas romanas de los diferentes núcleos urbanos del territorio onubense. En 
este período es cuando la propuesta La arquitectura doméstica urbana en época romana en la provincia Baetica, defendida por A. Gómez (2006), postuló el escaso impacto que el estudio de la casa había tenido para la historiografía tradicional y se acomete por primera vez una obra de síntesis y conjunto en la que queda recogida la edilicia doméstica de Onoba, Ilipla y Arucci (Gómez 2010). Si bien es cierto que este trabajo supuso la puesta al día de las investigaciones y la compilación de un ingente volumen de información sobre las construcciones domésticas, sin embargo, no se consiguieron paliar algunas de las carencias documentales como la transición y el epílogo a la ocupación romana, ni la elaboración de un discurso histórico que hilvanara el análisis arquitectónico, los programas ornamentales, la cultura material y la inserción en la trama urbana como factores explicativos de primer orden en las investigaciones recientes sobre las viviendas urbanas de la Hispania romana (Correia, 2013).

En el último cuarto de centuria (1990-2015) la documentación arqueológica relativa al fenómeno urbano en el sector occidental del Conventus Hispalensis se ha multiplicado exponencialmente, posibilitando la identificación definitiva de algunos núcleos urbanos como Ituci y Ostur (Campos y Bermejo, 2013, 8), a la vez que recientes aportaciones testimoniaron la imposibilidad de negar el desarrollo urbanístico de asentamientos ya conocidos, como el caso de Vrium (Schattner, 2007, 207-226; Gimeno y Stylow, 2007, 227-234; Campos et alii, 2013, 200). A pesar de que los estudios sobre la arquitectura doméstica de Ituci, Ostur y Vrium se encuentran aún en un estado embrionario resulta necesario incorporar los datos disponibles en el corpus documental de las ciudades occidentales del territorio onubense. Asimismo en el último decenio (2005-2015) varios trabajos de investigación sobre las viviendas urbanas de otras provinciae han sido defendidos y publicados con la aportación de novedosos enfoques metodológicos dignos de consideración (Uribe, 2015; Cortés, 2014; Bermejo, 2015; Corrales, 2016). A estos recientes trabajos cabría incorporar las nuevas perspectivas expresadas en la Reunión Científica «Privatorum Aedificiorum Ratiocinationes» (Vitr. De Arch., VI, praef., 7). Aspectos histórico-arqueológicos de la edilicia doméstica urbana en Hispania», Mateos, P., Corrales, A. y Moreno, M. (coords.) que tuvo lugar en Mérida en el año 2014, organizadas desde el Instituto de Arqueología de Mérida y la Universidad de Granada. La celebración de dichas jornadas respondía a la necesidad de reflexionar sobre el estado actual de las investigaciones y dar a conocer los nuevos avances en los paisajes domésticos de los núcleos urbanos hispanos.

Las perspectivas de futuro deben conjugar, pues, una metodología de amplio espectro. Así a los procedimientos consuetudinarios como la ampliación de la búsqueda de fuentes de información o la creación de catálogos, cabe implementar procedimientos de laboratorio con las Tecnologías de la Información y la
Comunicación. En este sentido, la creación de bases de datos espaciales en el entorno de los Sistemas de Información Geográfica se impone como la herramienta moderna en Arqueología para coordinar un ingente volumen de información en un marco de trabajo topográfico cerrado. Asimismo la aplicación de la fotogrametría digital y el fotomodelado en 3 Dimensiones aportan precisión y la obtención de información mesurable de las imágenes que resultan vitales para la documentación gráfica del patrimonio (Corrales, 2016, 35).

Finalmente, el concurso de los Sistemas de Información Geográfica posibilitará la creación de planos temáticos que facilitarán la aproximación a una lectura urbanística diacrónica del paisaje doméstico, permitiendo el análisis de las viviendas en diferentes rangos: la escala micro-espacial, destinada al examen de la casa y sus diferentes ambientes; la escala mesoespacial, consagrada a las construcciones domésticas y su relación con la trama urbana en que se inserta; y la escala macro-espacial, centrada en la problemática de los edificios residenciales y el territorio. Todo ello con el objetivo último de ofrecer un marco de interpretación verosímil del fenómeno de la dinámica de ocupación y modo de vida romano en las ciudades occidentales del Conventus Hispalensis.

\author{
Dr. Álvaro Corrales Álvarez \\ Prof. Dr. Javier Bermejo Meléndez \\ Prof. Dr. Juan Manuel Campos Carrasco \\ Investigadores Grupo de Investigación PAI HUM 132 \\ «Vrbanitas. Arqueología y Patrimonio» \\ Campus de El Carmen \\ Facultad de Humanidades \\ Avda. Tres de Marzo, s/n \\ Universidad de Huelva \\ 21071 Huelva \\ alvarcorrales@uhu.es \\ javier.bermejo@dhis1.uhu.es \\ campos@uhu.es
}

\section{FUENTES DOCUMENTALES}

Petronio, El Satiricón, traducción y notas de Lisardo Rubio Fernández; presentación de Carmen Codoñer Merino, 2008, Barcelona.

\section{BIBLIOGRAFÍA}

ABAD CASAL, L., 1975: «Pintura romana de Itálica», en Actas del XIII Congreso Nacional de Arqueología, 883893, Zaragoza.

ANDREWS, J., 2006: The use and development of upper floors in houses at Herculaneum, University of Reading, Tesis doctoral inédita.

AMO Y DE LA HERA, M. DEL, 1976: «Restos materiales de la población romana de Onuba», Huelva Arqueológica, II, 11-196.

ARNOLD, E., 2012: Memoria Preliminar: Actividad Arqueológica de Urgencia en C/ Altozano $n^{\circ} 3$, Niebla, 
Huelva, Delegación Provincial de Cultura de Huelva de la Junta de Andalucía, Registro 19/03/2012, 63 páginas.

BALIL ILLANA, A., 1959a: La casa romana en España, Madrid.

BALIL ILLANA, A., 1959b: «La casa romana en España», Actas del V Congreso Nacional de Arqueología, 284287, Zaragoza.

BALIL ILLANA, A., 1974: Casa y urbanismo en la España Antigua, IV, Studia Archaeologica 28, Valladolid.

BELÉN, Ma . y ESCACENA, J.L., 1990: «Niebla (Huelva). Excavaciones junto a la Puerta de Sevilla (1978-1982). La cata 8», Huelva arqueológica, XII, 167-306.

BELÉN, Ma ., FERNÁNDEZ, M., AMO, M. DEL, BALBÍN, R. y TEJERA, A., 1983: «Excavaciones en Niebla (Huelva)», Actas del XVI Congreso Nacional de Arqueología, 971-994, Zaragoza.

BERMEJO MELÉNDEZ, J., 2010: «LLa curia del Foro de Arucci/Turobriga〉, en J.A Pérez y E. Romero (eds.), $I V$ Encuentro de Arqueología del Suroeste Peninsular, 9991010, Huelva.

BERMEJO MELÉNDEZ, J., 2013: Arucci y Turobriga. Civitas et territorium. Un modelo de implantación territorial y municipal en la Baeturia Celtica, Huelva.

BERMEJO MELÉNDEZ, J., 2014: «UUn santuario a las Matres en el Foro de Arucci: la constatación de las Rixamae en la Baeturia Celtica〉, Onoba, 2,107-125.

BERMEJO, J. y CAMPOS, J.M., 2013a: «El mundo urbano romano en el occidente de la Bética. Balance y perspectivas de futuro»), en J.M. Campos y J. Bermejo (eds.), Roma en el occidente de la Baetica. Civitas et ager en el territorio onubense, 393-394, Roma.

BERMEJO, J. y CAMPOS, J.M., 2013b: «La implantación de Roma en las tierras del Suroeste», en J.M. Campos y J. Bermejo (eds.), Roma en el occidente de la Baetica. Civitas et ager en el territorio onubense, 87-108. Roma.

BERMEJO, J. y CAMPOS, J.M., 2013c: «Municipalización al oeste de la Bética: de las promociones augusteas a la extensión del ius latii flavio», en J.M. Campos y J. Bermejo (eds.), Roma en el occidente de la Baetica. Civitas et ager en el territorio onubense, 109-134, Roma.

BERMEJO, J. y CAMPOS, J.M., 2014: «El foro de Arucci, un modelo de arquitectura forense en el contexto provincial de la Bética〉, en J.M. Álvarez, T. Nogales e I. Rodá (eds.), Actas del XVIII Congreso Internacional de Arqueología Clásica. Centro y periferia en el Mundo Clásico, 1561-1566, Mérida.

BERMEJO, J., GÓMEZ, A. y CAMPOS, J. M., 2014: «Urbanismo aruccitano: el trazado regulador de la domus Norte», Revista d'Arqueología de Ponent, 24, 41-50.

BERMEJO TIRADO, J., 2015: Arqueología de los espacios domésticos romanos: Condiciones de vida y sociedad en la Meseta Nordeste durante el período imperial, Soria.

BLANCO FREIJEIRO, A., 1978: Mosaicos romanos de Itálica (I). Corpus de Mosaicos romanos de España 2, Madrid.

BLANCO, A. y LUZÓN, J.Mª., 1966: «Mineros antiguos españoles», Archivo Español de Arqueología, 39, $\mathrm{n}^{\circ}$ 113-114, 73-88.
BLÁZQUEZ MARTÍNEZ, J. Mª., 1993: Mosaicos romanos de España, Madrid.

CAMPOS CARRASCO, J.M., 1989: «Estructura urbana de la Colonia Iulia Romula Hispalis en época republicana», Habis, 20, 245-262.

CAMPOS CARRASCO, J.M., 2001-2002: «La ciudad romana de Onuba (Huelva). Una revisión arqueológica», AnMurcia, 16-17, 329-340.

CAMPOS CARRASCO, J.M., 2002: «Génesis y evolución del fenómeno urbano en el territorio onubense», $S P A L$, 11, 161-168.

CAMPOS CARRASCO, J.M., 2011: Onoba Aestuaria. Una ciudad portuaria en los confines de la Baetica, Huelva.

CAMPOS, J.M. y BERMEJO, J., 2013: «Las ciudades romanas del territorio onubense: la culminación de un proyecto», en J.M. Campos y J. Bermejo (eds.), Roma en el occidente de la Baetica. Civitas et ager en el territorio onubense, 7-12, Roma.

CAMPOS, J.M., CASTIÑEIRA, J., GARCÍA, J.M. y BORJA, F., 1991: «Arqueología y evolución del paisaje. Un proyecto georqueológico en la Tierrra Llana de Huelva», Cuadernos del Suroeste, 2, 43-70.

CAMPOS, J.M. y GÓMEZ, F., 2000: Carta de Riesgo de la ciudad de Huelva, Delegación Provincial de Cultura de Huelva de la Junta de Andalucía, Registro 06/07/2000, 818 páginas.

CAMPOS, J.M., GÓMEZ, F. y PÉREZ, J.A., 2006: ILIPLANIEBLA. Evolución urbana y ocupación del territorio, Huelva.

CAMPOS, J.M., PÉREZ, J.A., GÓMEZ, F. y LÓPEZ, M., 1998: «Intervenciones arqueológicas para la redacción de un proyecto de puesta en valor en los restos de la Puerta de Sevilla y del Desembarcadero (Niebla, Huelva)», Anuario de Arqueología de Andalucía, 98.II, 135-145.

CAMPOS, J.M., RODRIGO, J.M. y VIDAL, N.O., 2002: «El urbanismo de Niebla desde la Protohistoria hasta el mundo moderno», Huelva en su historia, $2^{\mathrm{a}}$ época, vol.9, 35-54.

CAMPOS, J.M., TEBA, J.A., CASTIÑEIRA, J. y BEDIA, J., 1990: «La documentación arqueológica para el estudio de la romanización en la provincia de Huelva»», Huelva en su historia, 3, 67-106.

CAMPOS, J.M. y VIDAL, N.O., 1999: «El urbanismo de las ciudades romanas del territorio onubense. El caso de ITUCCI», en P. Bueno y R. Balbín (coords.), Actas II Congreso de Arqueología Peninsular, Tomo IV, 229236, Zamora.

CAMPOS, J.M. y VIDAL, N.O., 2003: «Las ciudades hispano-romanas del territorio onubense. Estado de la cuestión», Revista d'Arqueología de Ponent, 13, 41-81.

CAMPOS, J.M., VIDAL, N.O., BERMEJO, J. y DELGADO, S., 2013): «Las ciudades occidentales del Conventus Hispalensis. Civitates, Municipia y Colonia», en J.M. Campos y J. Bermejo (eds.), Roma en el occidente de la Baetica. Civitas et ager en el territorio onubense, 135-226, Roma.

CAMPOS, J.M., VIDAL, N.O. y GÓMEZ, A., 2010: «Los mosaicos romanos del territorio onubense. Corpus 
documental», en J.A. Pérez y E. Romero (eds.), IV Encuentro de Arqueología del Suroeste Peninsular, 10341065, Huelva.

CAMPOS, J.M., GÓMEZ, A. y VIDAL, N.O., 2008: $L a$ ruta del mosaico romano. El Sur de Hispania (Andalucía y Algarve), Faro.

CARRIAZO Y ARROQUIA, J. DE M., 1934-1935: «Estado actual de las excavaciones de Itálica. La manzana del gimnasio», Anuario del Cuerpo Facultativo de Archiveros, Bibliotecarios y Arqueólogos, 2-19.

CARRIAZO Y ARROQUIA, J. DE M., 1935: «LLes fouilles d'Italica. Aperçu historique», Bulletin de l'Office International des Instituts d'Archéologie et d'Histoire de l'Art, Vol. I, núm. 3, 25-33.

CHAVES TRISTÁN, F., 1974: «Las monedas de la Casa del Planetario (Itálica)», Habis 5, 205-211.

CHIC GARCÍA, G., 2007: «La zona minera del Suroeste de Hispania en época Julio-Claudia», en J.A Pérez y A. Delgado (eds.), Las minas de Río Tinto en época JulioClaudia, 11-36, Huelva.

CORREIA, V., 2013: A arquitectura doméstica de Conimbriga e as estruturas económicas e sociais da cidade romana, Coimbra.

CORRALES ÁlVAREZ, A., 2011: «La arquitectura doméstica en Augusta Emerita. 100 años de investigación arqueológica», en J.M. Álvarez y P. Mateos (eds.), Actas Congreso Internacional 1910-2010: el yacimiento emeritense, 311-326, Mérida.

CORRALES ÁLVAREZ, A., 2012: «Arquitectura doméstica y urbanística en Augusta Emerita〉, Antesteria, 1, 255-266.

CORRALES ÁLVAREZ, A., 2016: La arquitectura doméstica de Augusta Emerita, Madrid.

CORTÉS VICENTE, A., 2014: L'Arquitectura domèstica d'època tardorepublicana i altimperial a les ciutats romanes de Catalunya, Barcelona.

FERNÁNDEZ GÓMEZ, F., 1998: Las excavaciones de Itálica y D. Demetrio de los Ríos a través de sus escritos, Córdoba.

FERNÁNDEZ, J., RUFETE, P. y GARCÍA, C., 1992: «Nuevas evidencias de Onuba», CuPAUAM, 19,289-317.

FERNÁNDEZ, J., GARCÍA, C., y RUFETE, P., 1997: De Tartessos a Onuba. 15 años de arqueología en Huelva, Huelva.

FERNÁNDEZ, L., CAMPOS, J.M. y VIDAL, N.O., 2013: «El mundo funerario en la ciudad romana de Onoba: las manifestaciones arquitectónicas de la necrópolis Norte», Onoba, 1, 175-186.

GARCÍA Y BELLIDO, A., 1960: Colonia Aelia Augusta Italica, Madrid.

GASSNER, V., 1986: Die kaufläden in Pompeii, Wien.

GIMENO, H. y STYLOW, A., 2007: «Inscripciones monumentales de la Corta del Lago», en J.A. Pérez y A. Delgado (eds.), Las minas de Río Tinto en época JulioClaudia, 227-234, Huelva.

GÓMEZ RODRÍGUEZ, A., 2008: «La arquitectura doméstica de la ciudad hispanorromana de Turobriga (Aroche, Huelva)», Vipasca, 2, 364-374.
GÓMEZ RODRÍGUEZ, A., 2010: La arquitectura doméstica urbana en época romana en la Provincia Baetica, Huelva.

GÓMEZ, A., BERMEJO, J. y MEDINA, N., 2010: «Nuevos datos para la interpretación del urbanismo en la ciudad hispanorromana de Arucci/Turobriga: la Casa Norte», Romula, 9, 155-175.

GÓMEZ, F. y CAMPOS, J.M., 2000: «Arqueología urbana en Huelva. Las últimas evidencias», Anales de Arqueología Cordobesa, 11, 155-176.

GUERRERO, O., GONZÁLEZ, D. y GOYANES, S., 2004: «Intervención arqueológica de urgencia en solar sito en C/ Arquitecto Pérez Carasa, 1 Esquina C/ Vázquez López, 4 (Huelva) », Anuario Arqueológico de Andalucía, 2001, 519-526, Sevilla.

LEÓN-CASTRO ALONSO, P., 1977-1978: «Notas sobre técnica edilicia en Itálica», Archivo Español de Arqueología, 50-51, 143-152.

LEÓN, P. y RODRÍGUEZ, P., 1993: «La ciudad hispanorromana en Andalucía», en M. Bendala, (coord.), La ciudad hispanorromana, 12-53, Barcelona.

LUZÓN NOGUÉ, J.Mª., 1970: Breve guía para una visita a las ruinas de Itálica, Sevilla.

LUZÓN NOGUÉ, J. Mª., 1982: «Consideraciones sobre la urbanística de la ciudad nueva de Itálica», Excavaciones Arqueológicas en España, 121, 75-95.

LUZÓN, J.M . y RUIZ, D., 1970: «El poblado minero romano de Río Tinto», Habis, 1, 125-138.

MACIAS SOLÉ, J., 2004: «Arquitectura doméstica», en X. Dupré (ed.), Tarragona: colonia iulia urbs triumphalis Tarraco, 73-82, Roma.

MAÑAS ROMERO, I., 2004: «El mosaico italicense de Hylas», Romula, 3, 103-124.

MAÑAS ROMERO, I., 2011: Mosaicos romanos de Itálica (II), Madrid.

MEDINA ROSALES, N., 2010: «El espacio termal de la ciudad hispanorromana de Turobriga (Aroche, Huelva)», en J.A. Pérez y E. Romero (eds.), IV Encuentro de Arqueología del Suroeste Peninsular, 1011-1033, Huelva.

MERCADO, L. y MEJÍAS, J.C., 1999: Informe técnico preliminar. Intervención arqueológica de urgencia. Solar $n^{\circ} 1$ de Plaza San Pedro, Delegación Provincial de Cultura de Huelva de la Junta de Andalucía, Registro 21/05/1999, 215 páginas.

PACKER, J., 1971: The insulae of imperial Ostia, Roma.

PARIS, P., BONSOR, G., LAUMONIER, A., RICARD, R. y DE MERGELINA, C., 1923: Fouilles (Bolonia, province de Cadix) (1917-1923). La ville et ses dépendances. Fouilles de Belo I, París.

PARLADÉ Y HEREDIA, A., 1934: Excavaciones en Itálica. Campañas de 1925 a 1932, Junta Superior de Excavaciones y Antigüedades, Madrid.

PÉREZ MACÍAS, J.A., 1986: «El poblado minero de Río Tinto. Determinantes de su dispersión», Arqueología Espacial, 10, 135-148.

PÉREZ, J.A., CAMPOS, J.M. y GÓMEZ, F., 2000: «Niebla de Oppidum a Madina», Anales de Arqueología Cordobesa, 11, 91-122. 
PÉREZ, J.A., y DELGADO, A., 2007: «Los metalla de Río Tinto en época Julio-Claudia», en J.A. Pérez y A. Delgado (eds.), Las minas de Río Tinto en época JulioClaudia, 37-184, Huelva.

PÉREZ, J.A. y DELGADO, A., 2011: «Ingeniería minera antigua y medieval en el suroeste ibérico», Boletín Geológico y Minero, 122 (1), 3-16.

PÉREZ, J.A., y DELGADO, A., 2012: «Paisaje y territorio de Riotinto en época romana», en M. Zarzalejos, P. Hevia, y L. Mansilla (eds.), Paisajes mineros antiguos en la Península Ibérica. Investigaciones recientes y nuevas lineas de trabajo. Homenaje a Claude Domergue, 4768, Madrid.

PÉREZ, J.A., GUERRERO, O., GONZÁLEZ, D. y GOYANES, S., 2003: «Nuevos elementos de análisis sobre Onoba (Huelva)», Saguntum, 35, 159-176.

PÉREZ, J.A., MARTINS, A., BUSTAMANTE, M. y DELGADO, A., 2009: «De Praesidium a vicus Metallum: el poblado minero en el suroeste peninsular», en J. González y P. Pavón (eds.), Andalucía Romana y Visigoda. Ordenación y Vertebración del territorio, 37-64, Roma.

REBOLLO CONDE, $M^{\text {a }}$.T., 1987: «Informe sobre los trabajos realizados para la readaptación de la zona arqueológica próxima a la Puerta de Sevilla», Anuario Arqueológico de Andalucía/86, vol. III, 516-520.

REBOLLO CONDE, Ma.T., 1990: Informe sobre los trabajos realizados para la readaptación de la zona arqueológica próxima a la Puerta de Sevilla, Delegación Provincial de Cultura de Huelva de la Junta de Andalucía, 18 páginas.

ROBLES ESPARCIA, S., 2011: La ciudad hispanorromana de Ostur, Trabajo Fin de Máster, Universidad de Huelva, inédito.

ROBLES ESPARCIA, S., 2012: «La historia de las investigaciones de Ostur: una introducción para su estudio»», Romula, 11, 95-114.

ROBLES, S. BERMEJO, J. y CAMPOS, J.M., 2012-2013: «La ciudad hispanorromana de Ostur», Anales de Arqueología Cordobesa, 23-24, 75-94.

RODRÍGUEZ HIDALGO, J.M., 1991: «Dos ejemplos domésticos en Traianopolis (Itálica): las Casas de los Pájaros y de la Exedra», La casa urbana hispanorromana, 291-302, Zaragoza.

ROLDÁN GÓMEZ, L., 1991: «La Casa de la Exedra de Itálica (Santiponce, Sevilla), un intento de valoración espacial a través de las técnicas constructivas»), en $L a$ casa urbana hispanorromana, 303-311, Zaragoza.

RUFETE, P. y GARCÍA, C., 1997: «Excavaciones arqueológicas realizadas en Huelva», Anuario Arqueológico de Andalucía, 1993,74-78.
RUIZ ACEVEDO, J.M., 2010: El suroeste peninsular en las fuentes literarias grecolatinas: el territorio onubense, Huelva.

RUIZ, J.M. y BERMEJO, J., 2013: «Scripta manent. El Occidente Bético en las fuentes Grecolatinas»), en J.M. Campos y J. Bermejo (eds.), Roma en el occidente de la Baetica. Civitas et ager en el territorio onubense, 19-56, Roma.

SCHATTNER, T., 2007: «Dos estatuas romanas en el Museo Minero de Riotinto», en J.A. Pérez y A. Delgado (eds.), Las minas de Río Tinto en época Julio-Claudia, 207-226, Huelva.

TOSCANO, C.M., BERMEJO, J. y GÓMEZ, F., 2013: «Turdetanos, Púnicos y Célticos: La situación previa a la llegada de Roma en el Interfluvio Guadiamar-Guadiana»), en J.M. Campos y J. Bermejo (eds.), Roma en el occidente de la Baetica. Civitas et ager en el territorio onubense, 57-86, Roma.

URIBE AGUDO, P., 2015: La arquitectura doméstica urbana romana en el valle medio del Ebro (ss. I a.C. - III d.C.), Bordeaux.

VAQUERIZO GIL, D., 2004: «Arquitectura doméstica y funeraria», en X. Dupré (ed.), Córdoba. Colonia Patricia Corduba, 81-94, Roma.

VIDAL TERUEL, N.O., 1996: Tejada la Nueva en el marco histórico de la Tierra Llana de Huelva: Análisis histórico-arqueológico, Trabajo de investigación de Tercer Ciclo, Universidad de Huelva, inédito.

VIDAL TERUEL, N.O., 1997: «La economía de Tejada la Nueva (Huelva) a través de las fuentes arqueológicas, numismáticas y textuales», Huelva en su historia, 2, 31-45.

VIDAL TERUEL, N.O., 2002: «La ocupación del territorio onubense en época romana: estado de la cuestión», Huelva en su historia, 9, 55-76.

VIDAL TERUEL, N.O., 2007: Análisis arqueológico de la romanización del territorio onubense, Huelva.

VIDAL, N.O., GÓMEZ, A. y CAMPOS, J.M., 2007: «De musivaria onubense: Mosaicos geométricos y con iconografía agrícola y cinegética procedentes de Ilipla (Niebla) e Ituci (Tejada la Nueva)», Anales de Arqueología Cordobesa, 18, 291-316.

WALLACE-HADRILL, A.,1991:« Houses and households: Sampling Pompeii and Herculaneum», en B. Rawson (ed.), Marriage, divorce and children in Ancient Rome, 191-227, Canberra.

WALLACE-HADRILL, A., 1997: «Rethinking the Roman atrium house», en A. Wallace-Hadrill y R. Laurence (eds.), Domestic space in the roman world: Pompeii and Beyond, JRA Suppl. 22, 219-240, Portsmouth. 